\title{
Orbital rhabdomyosarcoma: improved survival with combined pulsed chemotherapy and irradiation
}

\author{
SALAHUDIN Y A GHAFOOR' AND JOHN DUDGEON ${ }^{2}$ \\ From the 'Tennent Institute of Ophthalmology, University of Glasgow, and the ${ }^{2}$ Royal Hospital for Sick \\ Children, Glasgow
}

SUMmARY Three cases of embryonal orbital rhabdomyosarcoma are presented in which two cases had intracranial extension. All three are alive and well on follow-up several years after completing a 12-month course of combined pulsed chemotherapy and irradiation. The improved prognosis even in parameningeal involvement is emphasised.

\begin{abstract}
Although orbital rhabdomyosarcoma is the commonest primary orbital tumour in childhood, it is still a rare condition for the practising ophthalmologist, with an annual incidence of 1 in 4.4 million. Combined pulsed chemotherapy and radiotherapy has improved the survival rate when lesions are confined to the orbit to $90 \%$ in contrast to $66 \%$ with radiotherapy alone.' With bone destruction and extension, however, the overall survival with the combined therapy is $65 \%$. In cases that failed to respond satisfactorily death usually occurred within 18 months.

The modern approach to a child presenting with suspected rhabdomyosarcoma is early diagnosis by biopsy, accurate pretreatment staging, local control of the primary tumour, and eradication of micrometastases. The combined use of the antimetabolite vincristine, antitumour antibiotics actinomycin D and adriamycin, and the alkylating agent cyclophosphamide following irradiation, has permitted more complete tumour eradication in the orbit and suppression of potential metastasis. An interdisciCorrespondence to S Y A Ghafoor, FRCS Glas, Tennent Institute of Ophthalmology, University of Glasgow, Western Infirmary, Glasgow G11 6NT.
\end{abstract}

Table 1 Survival of rhabdomyosarcoma patients

\begin{tabular}{|c|c|c|c|c|c|}
\hline Case & Age & Sex & $\begin{array}{l}\text { Histology } \\
\text { type }\end{array}$ & $\begin{array}{l}\text { IRS } \\
\text { stage }^{*}\end{array}$ & $\begin{array}{l}\text { Survival Since } \\
\text { diagnosis } t\end{array}$ \\
\hline 1 & 8 & $\mathbf{F}$ & Embryonal & IIB & $5 \mathrm{yr}$ \\
\hline 2 & 7 & $\mathrm{M}$ & Embryonal & III & 3 yr $8 \mathrm{mo}$ \\
\hline 3 & 3 & $\mathbf{M}$ & Embryonal & III & 4 yr $10 \mathrm{mo}$ \\
\hline
\end{tabular}

*IRS=Intergroup Rhabdomyosarcoma Study. †October 1984. plinary team approach in the management of such cases is essential.

We report three cases which presented in the West of Scotland. All three patients are alive and well after completing a 12-month combined therapy course (Table 1).

\section{Case reports}

CASE 1

An 8-year-old girl presented on 28 September 1979 with painful proptosis of the right eye and marked chemosis as well as restriction of movement on dextroversion (Fig. 1). The visual acuity in the right eye was $6 / 6$ and in the left $6 / 9$. A retrobulbar mass was suspected; a biopsy proved the lesion to be a rhabdomyosarcoma. $X$-ray of the orbit, tomography, ultrasound, and CT scan disclosed destruction of the lateral wall and inferior margin of the right orbit as

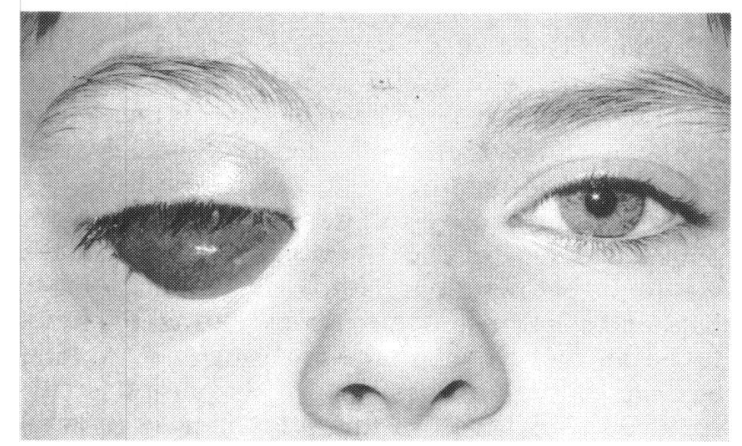

Fig. 1 Case 1. Right orbital proptosis with chemosis. 


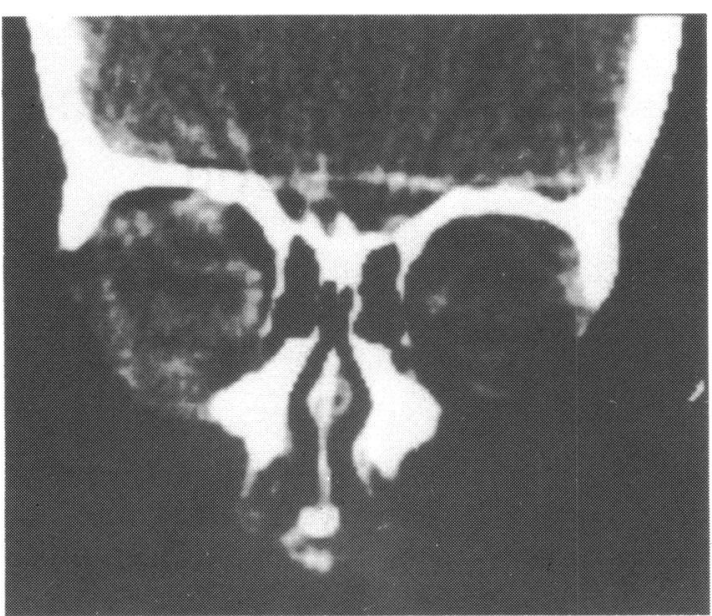

Fig. 2 Case 1. CT scan (coronal section) showing extension of orbital lesion laterally.

well as that of the lateral wall of the right antrum and malar bone (Fig. 2). Screening tests for metastasis included skeletal survey, chest $x$-ray, blood smears, liver scan, bone scan, abdominal ultrasound, liver and spleen scan, and bone marrow trephine.

The lesion was staged IIB according to the American Intergroup Study classification. ${ }^{2}$ Initial weekly chemotherapy consisted of vincristine $\left(1.5 \mathrm{mg} / \mathrm{m}^{2}\right.$ intravenously), adriamycin $\left(40 \mathrm{mg} / \mathrm{m}^{2}\right.$ intravenously) and cyclosphosphamide $\left(200 \mathrm{mg} / \mathrm{m}^{2}\right.$ intravenously). After two doses radiotherapy was given to the residual tumour at a dose of 4000 rads. Pulsed chemotherapy with vincristine, cyclophosphamide, and adriamycin intravenously was given at fortnightly intervals until the total dose of adriamycin was $400 \mathrm{mg}$. There was a pause of two weeks between radiotherapy and recommencement of chemotherapy, then a fortnightly regimen intravenous of vincristine $\left(1.5 \mathrm{mg} / \mathrm{m}^{2}\right), \quad$ cyclophosphamide $\left(400 \mathrm{mg} / \mathrm{m}^{2}\right)$, and Actinomycin $\mathrm{D}\left(1.0 \mathrm{mg} / \mathrm{m}^{2}\right)$ was continued for a year.

The size of the tumour was monitored with serial CT scans. The ocular side effects initially were of a local nature, with eyelid skin reactions and conjunctival chemosis, but the right eye continued to be irritable, with marked corneal destruction, neovascularisation, and painful uveitis. Five months later it was still unresponsive to intensive therapy and was enucleated. No evidence of extension into the sinuses was found at operation. Pathological examination by light and electron and microscopy showed the lesion to be an embryonal rhabdomyosarcoma. A fuller account of the ultrastructure of this case has been reported elsewhere. ${ }^{3}$ In this study a close resemblance was found between the ultrastructural appear- ance of the undifferentiated rhabdomyosarcoma cells lacking the $\mathrm{z}$ banding found in this tumour and that of the primitive mesodermal cells in the extraocular muscle of a 9-10 cm human embryo.

On completion of the chemotherapy regimen the right socket was markedly contracted, and cosmetic reconstruction with dermofat graft was successfully done. Later side effects included recurrent epistaxis and sinusitis.

\section{CASE 2}

A 7-year-old boy presented in February 1981 with a painful right eye and two days later developed proptosis, ptosis, and limited ocular movement on adduction. The condition was initially thought to be related to ocular trauma sustained two days earlier.

The visual acuity in the right eye was only hand movements and in the left eye was $6 / 6$. In four days the right visual acuity deteriorated to no perception of light, and the right disc had become swollen. Right orbitotomy biopsy showed the swelling to be an embryonal rhabdomyosarcoma. CT scan showed this intraorbital lesion to be associated with erosion of the posterior and inferior orbital walls and maxillary antrum as well as intracranial extension into the middle cranial fossa. Investigations excluded metastasis to the lungs, skeleton, bone marrow, and cerebrospinal fluid. By the staging criteria of the American Intergroup Rhabdomyosarcoma Study the disease was classified as stage III.

Initial radiotherapy to the cranium only was given in a dose of 3000 rads over four weeks, followed by 2500 rads to the right orbit and cavernous sinuses over three weeks. Intravenous pulsed chemotherapy with vincristine $\left(1.6 \mathrm{mg} / \mathrm{m}^{2}\right)$, cyclophosphamide $(200$ $\left.\mathrm{mg} / \mathrm{m}^{2}\right)$, and actinomycin $\mathrm{D}\left(0 \cdot 3 \mathrm{mg} / \mathrm{m}^{2}\right)$ was followed by methotrexate $(12 \mathrm{mg})$, cytosine arabinoside $(50 \mathrm{mg})$, and hydrocortisone $(25 \mathrm{mg})$. In addition intrathecal hydrocortisone $(25 \mathrm{mg})$, methotrexate $(12 \mathrm{mg})$, and cytosine arabinoside $(50 \mathrm{mg})$ were administered at weekly intervals for eight weeks. Tumour regression was noted and monitored with CT scan. Six months later, however, the right eye developed painful keratitis, and on suspicion of endophthalmitis it was eviscerated. The chemotherapy regimen was continued until March 1982. Follow-up since then has shown no recurrence of the lesion. General side effects of this regimen included infection and stomatitis. Impairment of gait was attributed to vincristine neuropathy.

CASE 3

A 3-year-old boy presented in January 1980 with a two-week history of swelling over the right eyelid and proptosis. Four days later a tense mass in the upper lateral aspect of the orbit with displacement of the 


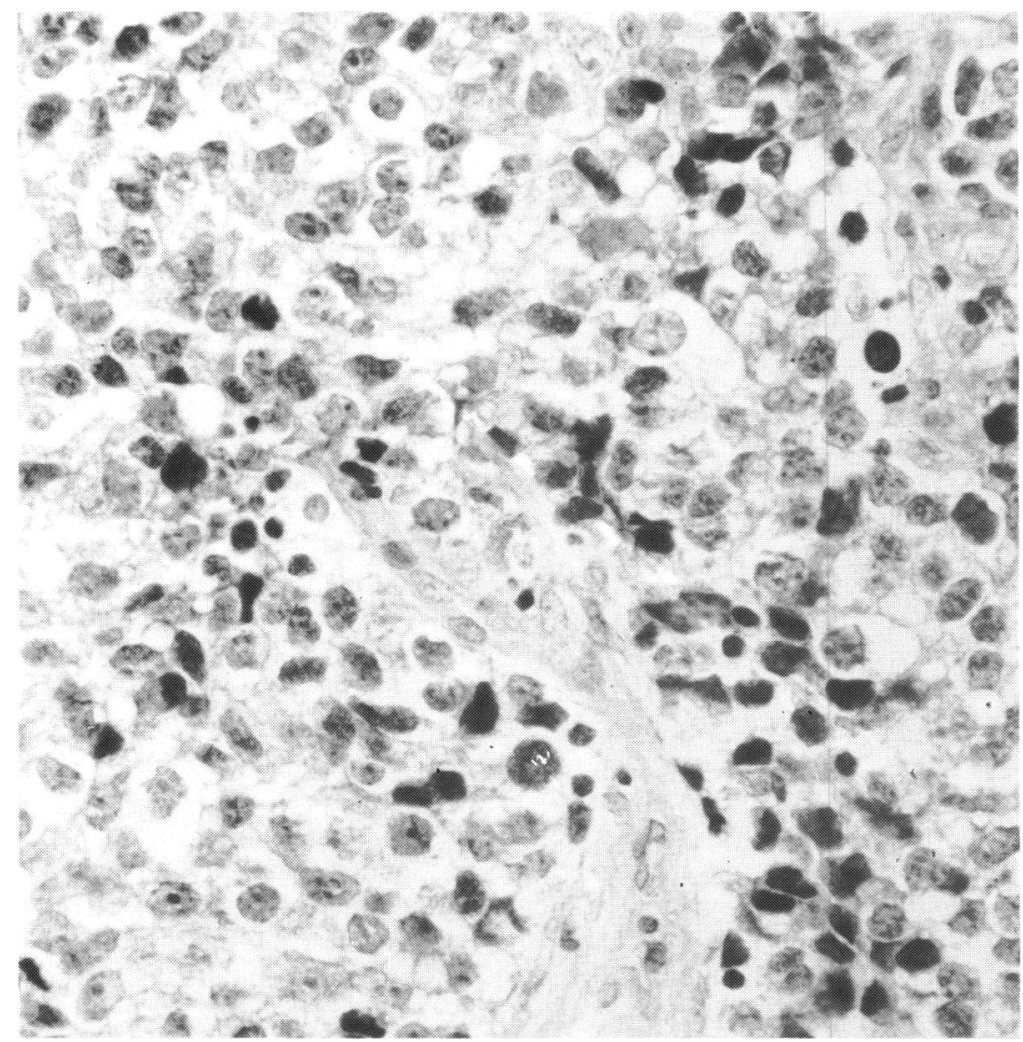

Fig. 3 Case 3. Histology of embryonal rhabdomyosarcoma. (Haematoxylin and eosin, $\times$ 450.)

globe was noted. $X$-ray showed an enlarged orbit. Anterior orbitotomy exploration revealed a pearly mass lying subperiosteally with bone destruction in the superolateral region of the orbit. Biopsy showed this to be an undifferentiated rhabdomyosarcoma (Fig. 3). A CT scan showed in addition extension to

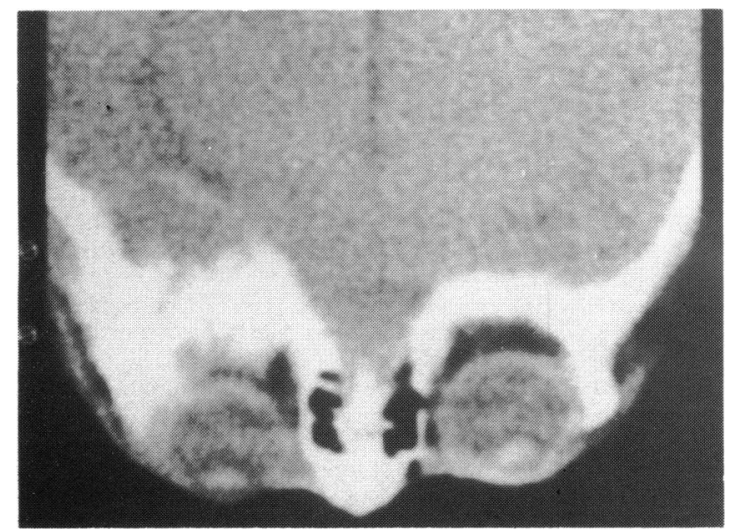

Fig. 4 Case 3. (T scan axial section) showing extension of orbital lesion into adjacent parameningeal tissues. the middle cranial fossa and temporal fossa (Fig. 4). These findings staged the lesion as stage III according to the criteria of the American Intergroup Rhabdomyosarcoma Study. Initially two courses of chemotherapy at weekly intervals with intravenous vincristine $\left(1.0 \mathrm{mg} / \mathrm{m}^{2}\right)$ were followed by radiotherapy. The total dose was 5000 rads spread in a fractionation pattern suitable to the child's age over a period of 67 days. External megavoltage irradiation with a high energy $(4 \mathrm{MeV})$ beam enabled the use of a sharp beam edge. Concurrently five weekly intravenous pulses of vincristine and cyclophosphamide at the above doses were administered, followed by 10 monthly intravenous pulses of adriamycin (total dose $260 \mathrm{mg}$ ), vincristine $\left(1.5 \mathrm{mg} / \mathrm{m}^{2}\right)$, and cyclophosphamide $\left(400 \mathrm{mg} / \mathrm{m}^{2}\right)$. The systemic side effects that occurred were those of abdominal pain, neutropenia and minor attacks of epistaxis. Serial CT scans showed regression of the cranial lesion and a small residual lesion at the orbit. On completion of the chemotherapy course in February 1982 no extension of the lesion was noted, but a posterior subcapsular cataract in the right eye developed. Extracapsular extraction of cataract with lens implantation was done. 


\section{Discussion}

Orbital rhabdomyosarcoma in children is of the embryonal type, and our three cases show the expected age incidence. The postulated origin of these tumours is from pluripotential mesenchymal elements. The commonest site of the lesion was emphasised by Frayer and Enterline ${ }^{4}$ as the superonasal quadrant of the orbit, but in two of our cases it was superotemporal. A history of trauma may lead the unwary to exclude the possibility of rhabdomyosarcoma. The differential diagnosis usually included infantile haemangioma, leukaemia, and neuroblastoma. Urgent biopsy is essential; the unequivocal diagnosis of embryonal type is possible only by electron microscopy demonstration of thick myosin filaments in the cytoplasm of rhabdomyosarcoma. ${ }^{5}$

Although extension to paranasal sinuses occurred in all three cases and also intracranial extension in two, there was complete regression following combined chemotherapy, leaving only a small residual 'lesion' in one case. Serial monotoring has not shown any evidence of activity.

Knowles et al. ${ }^{6}$ reviewed 162 cases of the four major series published on orbital rhabdomyosarcoma constituting $75 \%$ of the literature and found only 49 patients $(25 \%)$ who survived more than three years. Primary rhabdomyosarcoma in the orbit is uncommon compared with its incidence in other sites of the body. Jaffe et al. ${ }^{7}$ found only eight children $(13 \%)$ with orbital rhabdomyosarcoma in a series of 61 children affected by the tumour. Five out of these eight children with orbital lesions were alive over two and a half years later after combined orbital exenteration (radical neck dissection in three cases), radiation therapy, and actinomycin D (occasionally vincristine). Of these survivors three were stage II and two were stage I. The overall survival rate in Jaffe et al.'s series was best for primary orbital lesions $(63 \%)$ compared with the poorer prognosis of rhabdomyosarcoma in other sites. Sutow et al. ${ }^{8}$ found better survival rates $(91 \%)$ in their series in the Intergroup Rhabdomyosarcoma Study (IRS). In this series orbital lesions were found in $26 \%$ of patients with rhabdomyosarcoma. It has generally been agreed by those reporting this tumour" that a longterm survivor is a patient alive two years after diagnosis is made. By this definition our findings confirm such a good prognosis (Table 1).

Extension into parameningeal sites occurred in two cases. The CT scan is one of the best investigative tools not only for delineating the extent of such involvement but also for monitoring the effects of treatment. The importance of adequate treatment at this site cannot be overemphasised, as the meninges constituted the initial site of the disease recurrence. ${ }^{10}$ Primary rhabdomyosarcoma of the midcranial fossa itself is extremely rare."

Recent multiple therapeutic approaches which aim to conserve the eye with a planned programme to treat each case in an individual manner should give an even better prognosis. ${ }^{12}$ However, complications continue to occur with each type of treatment. Radiation keratitis and suspected endophthalmitis led to enucleation and evisceration in two of our cases. A contracture socket deformity needed further reconstruction. The systemic side effects of cytotoxic drugs included epistaxis, neutropenia, abdominal pain, and stomatitis, and in one case neuropathy due to vincristine. ${ }^{13}$ One could only speculate that perhaps the longer duration of the irradiation fractionation pattern was beneficial in case 3 .

Long-term complications of radiotherapy as a treatment of rhabdomyosarcoma have not been reported for orbital lesions, though reports of osteogenic sarcoma of the mandible and hypopituitarism after irradiation of nasopharyngeal rhabdomyosarcoma exist. ${ }^{7}$

Future developments in the management of this condition reside in reducing the toxicity of the present chemotherapeutic drugs. ${ }^{14}$ A recent approach involves the use of drugs to block the renal and bladder toxicity of cyclophosphamide. Another approach uses drugs such as lithium carbonate to stimulate the marrow production of leucocytes, thus reducing the marrow suppression of cytotoxic drugs. It has also been suggested that the development of analogues may reduce the toxicity of the active structure of cytotoxic drugs used in the treatment of rhabdomyosarcoma in children. The use of folic acid 'rescue' following massive doses of methotrexate is still under investigation and its value is unproved.

The authors thank Drs I M Hann and A A G Gibson and the Royal Hospital for Sick Children for their valuable advice and criticism, Dr Gibson for the photomicrograph and the Department of Medical Illustration, RHSC, for the photographs, and Miss Lorna Gow for typing the manuscript.

\section{References}

1 Kennedy RE. The lids, lacrimal apparatus and orbit. In: Hugh WF, ed. Year Book of Ophthalmology. Chicago: Year Book Publications, 1980: 9-13.

2 Gehan EA, Glover FN, Maurer HM, et al. Prognostic factors in children with rhabdomyosarcoma. Natl Cancer Inst Monogr 1981; 56: 83-92.

3 Behnasawi S, Downie T, Lee WR. Ultrastructure of a case of embryonal rhabdomyosarcoma of the orbit. Bull Ophthalmol Soc Egypt 1981; 74: 103-8.

4 Frayer WC, Enterline HT. Embryonal rhabdomyosarcoma of the orbit in children and young adults. Arch Ophthalmol 1959; 62: $20-4$.

$5 \mathrm{Kroll} \mathrm{AH}$. Fine structural classification of orbital rhabdomyosarcoma. Invest Ophthalmol Visual Sci 1967; 6: 531-40. 
6 Knowles DM, Jakobiec FA, Jones IS. Rhabdomyosarcoma. In: Duane T, ed. Clinical ophthalmology. Philadelphia: Harper and Row, 1981; 2: 2-3.

7 Jaffe N, Filler RM, Farber S, et al. Rhabdomyosarcoma in children. Improved outlook with a multidisciplinary approach. Am J Surg 1973; 125: 482-7.

8 Sutow WW, Lindberg RD, Gehan EA, et al. Three-year relapsefree survival rates in childhood rhabdomyosarcoma of the head and neck: Report of the Intergroup Rhabdomyosarcoma Study. Cancer 1982; 49: 2217-21.

9 Ehrlich F, Haas JE, Kiesewetter WB. Rhabdomyosarcoma in infants and children: factors affecting long term survival. J Pediatr Surg 1971; 6: 571-7.
10 Tefftt M, Fernandex C, Donaldson M. Incidence of meningeal involvement by rhabdomyosarcoma of the head and neck in children. Cancer 1978; 42: 253-8.

11 Deutsch M, Raymond L, Mercado R. Rhabdomyosarcoma of the middle cranial fossa. Cancer 1973; 31: 1193-6.

12 Tefft M, Lindberg RD, Gehan EA. Radiation therapy combined with systemic chemotherapy in children: local control in patients enrolled in the Intergroup Rhabdomyosarcoma Study. Natl Cancer Inst Monogr 1981; 56: 75-81.

13 Fraunfelder FT, Myer SM. Ocular toxicity of antineoplastic agents. Ophthalmology (Rochester) 1983; 90: 1-3.

14 Donaldson SS. In: Carter SK, Glastein E, Livingstone RB, eds. Principles of cancer treatment. New York: McGraw-Hill, 1981 859-61. 